Available online at http://jurnal.goretanpena.com/index.php/JSSR

\title{
MENINGKATKAN KEMAMPUAN BERPIKIR ANALITIS DAN KEMANDIRIAN MAHASISWA MENGGUNAKAN METODE PROJECT BASED LEARNING
}

\author{
Muthia Dewi $^{1}$, Sri Rezki Maulina Azmi ${ }^{2}$ Dailami $^{3}$ \\ STMIK Royal, Kisaran \\ e-mail: ${ }^{1}$ tiadaisu@gmail.com
}

\begin{abstract}
The purpose of this research is to improve the ability to think analytically and independently using the Project-Based Learning method. This type of research is Classroom Action Research. Where the operations in this study are divided into 4 stages in the form of planning, action, observation and reflection stages. The subjects in this study were students of class SI -2F STMIK Royal Kisaran and the objects in this study were analytical thinking skills and independence using project-based learning methods. The research instruments in collecting data were initial tests, learning outcomes tests, interviews and observations. Based on the results of the study, it was obtained that the total score obtained from the implementation of learning in cycle 1 in the class was categorized as less successful. The total score obtained in cycle 2 is categorized as less successful. The number of scores obtained from the implementation of Learning in cycle 3 failed. The number of scores obtained from the implementation of learning in cycle 4 is successful
\end{abstract}

Keywords: Berpikir Analitis, Kemandirian Mahasiswa, Project Based Learning

\begin{abstract}
Abstrak: Tujuan penelitian ini adalah untuk meningkatkan kemampuan berpikir analitis dan kemandirian mahasiswa menggunakan metode Project Based Learning. Jenis penelitian ini adalah Penelitian Tindakan Kelas. Dimana operasional dalam penelitian ini dijabarkan menjadi 4 tahap yang berupa siklus yaitu tahap perencanaan, tindakan, observasi dan refleksi. Subjek dalam penelitian ini adalah mahasiswa kelas SI -2F STMIK Royal Kisaran dan objek dalam penelitian ini kemampuan berpikir analitis dan kemandirian menggunakan metode project based learning. Instrumen penelitian dalam mengumpulkan data adalah tes awal, tes hasil belajar, wawancara dan observasi. Berdasarkan hasil penelitian diperoleh Jumlah skor yang diperoleh dari pelaksanaan Pembelajaran pada siklus 1 di kelas dikategorikan kurang berhasil. Jumlah skor yang diperoleh pada siklus 2 dikategorikan kurang berhasil. Jumlah skor yang diperoleh dari pelaksanaan Pembelajaran pada siklus 3 dikategorikan kurang berhasil. Jumlah skor yang diperoleh dari pelaksanaan Pembelajaran pada siklus 4 dikategorikan berhasil.
\end{abstract}

Kata kunci: Berpikir Analitis, Kemandirian Mahasiswa, Project Based Learning

\section{PENDAHULUAN}

Disadari atau tidak, pendidikan memegang peranan yang sangat penting dalam kehidupan. Pendidikan telah memberikan kontribusi mulai dari hal yang sederhana dalam kehidupan sehari-hari sampai hal yang kompleks dan abstrak. Untuk dapat melakukan semua itu diperlukan pemikir-pemikir yang kompeten, yang mampu menguasai dunia ilmu pengetahuan dan mampu berpikir tingkat tinggi (High Order Thinking) seperti berpikir analitis agar dapat memecahkan persoalan yang dihadapi. 
Available online at http://jurnal.goretanpena.com/index.php/JSSR

Kemampuan-kemampuan tersebut diperlukan dalam memecahkan masalah yang dihadapi di dalam kehidupan. Dengan mampunya individu memecahkan persoalan yang dihadapi maka secara otomatis akan menimbulkan sifat kemandirian pada diri individu tersebut. Untuk mendukung kemampuan berpikir analitis ini tentu harus dapat memahami konsep yang berkaitan dalam permasalahan yang akan dipecahkan. Pemahaman akan konsep menjadi modal yang cukup penting dalam melakukan pemecahan masalah, karena dalam menentukan strategi pemecahan masalah diperlukan penguasaan konsep yang mendasari permasalahan tersebut. Sebelum mahasiswa memiliki kemampuan menganalisis, terlebih dulu mahasiswa harus mempunyai ketiga level kemampuan sebelumnya yakni kemampuan mengingat, kemampuan memahami, dan kemampuan menerapkan (Ilma et al., 2017). kemampuan berpikir analitis ini ini mungkin berkaitan erat dengan kemandirian yang dimiliki mahasiswa. Mahasiswa mungkin memahami konsep tetapi ia lemah dalam menemukan ide-ide untuk pemecahan masalah, atau sebaliknya ia punya ideide pemecahan masalah akan tetapi pemahaman konsepnya kurang, atau bahkan kedua-duanya kurang. Oleh karena itu pemahaman konsep juga merupakan bagian penting dalam berpikir analitis. Agar kemampuan berpikir analitis dan kemandirian belajar dapat diterapkan, salah satu metode belajar yang dapat diterapkan adalah metode project based learning. Pembelajaran project based learning. terletak pada keikutsertaan mahasiswa dalam investigasi sekaligus pemecahan masalah, kegiatan tugastugas bermakna lain, dan memberi kesempatan mahasiswa untuk bekerja secara otonom dalam mengkonstruksi pengetahuan mereka sendiri, serta mencapai puncak untuk menghasilkan produk nyata.(Amini, 2015). Salah satu upaya yang dilakukan tersebut adalah bagaimana agar mahasiswa memiliki kecakapan dalam belajar.. Oleh karena itu perlu disadarkan tentang pengetahuan dan proses berpikir mereka. Mereka harus memiliki kesadaran bahwa mereka tahu tentang konsep yang melandasi untuk memecahkan suatu masalah, mereka sadar akan kelebihan dan kekurangan yang mereka miliki. Akibatnya dengan kesadaran ini diharapkan mereka mampu menyusun strategi untuk menyelesaikan permasalahan yang dihadapinya.

Kemampuan berpikir analitis merupakan domain ke empat dari revisi Taksonomi Bloom. Kemampuan berpikir analitis ditandai dengan beberapa kata kerja operasional seperti yang sudah dijelaskan sebelumnya. Dalam penelitian ini, pengukuran kemampuan berpikir analitis yang dipilih empat kemampuan yang sesuai dengan keterampilan proses yang dipilih yaitu mengorganisasikan, menganalisis, membuat garis besar, dan mendeskripsikan(Hasyim et al., 2018).

Model pembelajaran project based learning. sangat sesuai dengan Permendikbud No 66 tahun tentang Standar Penilaian, yang menyatakan bahwa untuk menilai kompetensi keterampilan dapat dilakukan melalui penilaian kinerja yang menuntut peserta didik mendemonstrasikan suatu kompetensi tertentu dengan menggunakan tes praktik, proyek dan 
Available online at http://jurnal.goretanpena.com/index.php/JSSR

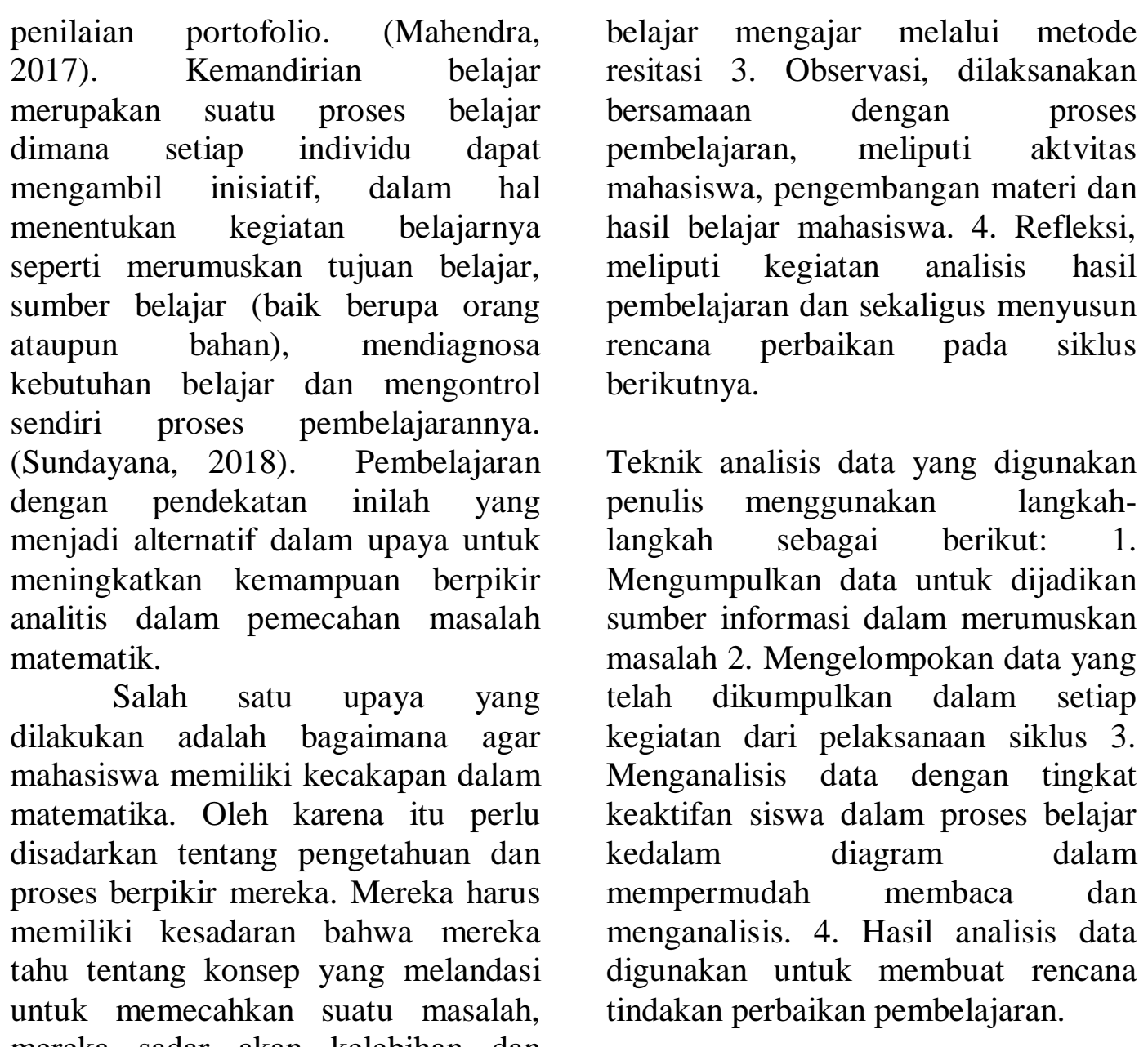
mereka sadar akan kelebihan dan kekurangan yang mereka miliki. Akibatnya dengan kesadaran ini diharapkan mereka mampu menyusun strategi untuk menyelesaikan permasalahan yang dihadapinya.

\section{METODE}

Subjek dalam penelitian ini adalah mahasiswa kelas SI -2F STMIK Royal Kisaran. Penelitian dilaksanakan pada semester genap tahun ajaran 2020/2021. Penelitian dilaksanakan melalui tiga siklus untuk melihat peningkatan hasil belajar mahasiswa. Siklus penelitian adalah: 1. Perencanaan, meliputi penetapan materi pembelajaran. 2. Pelaksanaan, meliputi seluruh proses kegiatan

\section{HASIL DAN PEMBAHASAN}

Untuk memperoleh gambaran pelaksanaan pembelajaran dapat diketahui dengan menganalisis hasil observasi dari ketiga siklus yang dilakukan berdasarkan rata-rata skor dengan perhitungan : Rata-rata skor $=$ Penafsiran : Rata-rata skor $1,0-1,9=$ Tidak berhasil Rata-rata skor 2,0 - 2,9 $=$ Kurang berhasil Rata-rata skor 3,0 4,0 = Berhasil

\section{SIMPULAN}

Berdasarkan hasil penelitian, diperoleh gambaran bahwa penerapan project based learning pada mahasiswa STMIK Royal Kisaran 
Available online at http://jurnal.goretanpena.com/index.php/JSSR

Tahun Ajaran 2020/ 2021 dapat meningkatkan kemampuan berpikir analitis dan kemandirian mahasiswa Dimana peningkatan diperoleh setelah siklus IV dilakukan.

\section{DAFTAR PUSTAKA}

Amini. (2015). Pengaruh Penggunaan Project Based Learning dan Motivasi belajar Terhadap hasil Belajar siswa kelas v SD. Prosiding Seminar Nasional Pendidikan Biologi, 4(2007), 339-345.

Hasyim, F., Fisika, P., Al, S., \& Surabaya, H. (2018). MENGUKUR KEMAMPUAN BERPIKIR ANALITIS DAN KETERAMPILAN PROSES SAINS MAHASISWA CALON GURU FISIKA STKIP AL HIKMAH SURABAYA MEASURING PRE-SERVICE PHYSICS TEACHERS' ANALYTICAL THINKING ABILITY AND SCIENCE PROCESS SKILLS OF STKIP AL HIKMAH SURABAYA (Vol. 2). http://ejournal.ikipveteran.ac.id/index.php/jipva

Ilma, R., Hamdani, A. S., \& Lailiyah, S.
(2017). Profil Berpikir Analitis Masalah Aljabar Siswa Ditinjau dari Gaya Kognitif Visualizer dan Verbalizer. Jurnal Review Pembelajaran Matematika, 2(1), 114. https://doi.org/10.15642/jrpm.2017. 2.1.1-14

Mahendra, I. W. E. (2017). Project Based Learning Bermuatan Etnomatematika Dalam Pembelajar Matematika. JPI (Jurnal Pendidikan Indonesia), 6(1), 106-114. https://doi.org/10.23887/jpiundiksha.v6i1.9257

Sundayana, R. (2018). Kaitan antara Gaya Belajar, Kemandirian Belajar, dan Kemampuan Pemecahan Masalah Siswa SMP dalam Pelajaran Matematika. Mosharafa: Jurnal Pendidikan Matematika, 5(2), 7584.

https://doi.org/10.31980/mosharafa. v5i2.262 